\title{
Creating social entrepreneurship in local government
}

\author{
Zahir $\operatorname{Irani}^{1 *}$ and \\ Tony Elliman ${ }^{2}$
}

${ }^{1}$ Brunel Business School, Brunel University, Uxbridge, U.K.; ${ }^{2}$ Department of Information Systems and Computing, Brunel University, Uxbridge, U.K.

${ }^{*}$ Correspondence: Zahir Irani, Brunel Business School, Brunel University, Uxbridge UB8 3PH, U.K.

Tel: + 44 (01895) 266 054;

E-mail: Zahir.irani@brunel.ac.uk
Received: 24 April 2008

Revised: 21 August 2008

Accepted: 22 August 2008

\begin{abstract}
The public sector is often considered synonym with inefficiency and a lack of motivation to be innovative. This paper seeks to contribute towards the literature surrounding social entrepreneurship in the public sector, through using institutional theory to underpin an e-Innovations model that promotes social entrepreneurship, while recognising how the adoption of innovation within the public sector is fostered. The proposed model seeks to serve as a process that threatens the conservative and risk-averse culture endemic in the public sector.
\end{abstract}

European Journal of Information Systems (2008) 0, 000-000. doi: $10.1057 /$ ejis.2008.35

Keywords: public sector; e-Innovations; social entrepreneurship

\section{Introduction}

Nye (1999) explains that U.K. local authorities are criticised for being inaccessible, unresponsive and essentially out of touch with citizen demands. In response to such claims, Central Government in the U.K., through both what was known as the Office of the Deputy Prime Minister (ODPM) and the Cabinet Office, launched multiple funding initiatives to create much needed inertia to support local Governments in creating their e-Government infrastructures. The Central Government public spending review of 2002/3 allocated £6bn over 3 years to Government electronic service delivery (e-Envoy, 2002). In turn, this created new market segmentation for the private Information Technology (IT) sector, which targeted local Government as potential purchasers of its new technology.

Although putting information on the internet, call it i-Government, has improved communication and access to information by the citizen, the use of connectivity and high speed internet access within a 'process' that offers service delivery to the public, loosely coined as e-Government, has, it would appear, so far delivered high cost for the tax-payer with limited success. Herein lies a paradox, which is based on two very different sectors, public and private, that have access to the same technology yet, reap different levels of performance. The private sector is not reliant on subsidies or, additional income streams yet, seems able to purchase and operate technology at a lower cost base thus, satisfying demanding customers (the unsatisfied ones simply walk away) and, provides dividends for its share holders. This environment is immensely competitive, where tight budgets set by prudent finance directors spark creativity and innovation, which leads to cost savings and creates a culture of change where new ideas and successes are rewarded. However, the public sector operates in a very different environment and resulting culture, which is protected from competing forces, lacks imagination and foresight for strategic planning, and where it would rather restructure its technology 
infrastructures than its organisational infrastructure (Irani et al., 2005, 2007, 2008 and Jones et al., 2006). These large bureaucratic public sector structures, grounded in years of tradition, are often unable to embrace change and thus possibly lack the environment for innovation, or any form of social entrepreneurship to thrive. Simply, while local governments have many rivals they do not compete, and thus there is no motivation to remain competitive in the quality of service delivery and, cost charged to the tax-payer for such services. A failure in bureaucracy by local Government simply represents incompetence, yet in the public sector it spells bankruptcy.

Today's society is driven by the active generation, diffusion and appropriation of new ideas. To ensure that the public sector is supported in developing a culture where innovation and reflection is encouraged, much care and attention needs to be directed towards defining appropriate skill sets for innovators as well as innovationmanagers. This level of proactive forward thinking management is charged with promoting change and fostering ideas for the good of the organisation and in delivery of best value to the citizen and hence tax-payer. This needs to be achieved while set against a back-drop of training and education within a process that encourages social entrepreneurship whist recognising the reserved organisational environment. It is in proposing such a process, where the authors of this paper claim to contribute towards both the literature and offer a practical model, that promotes the take-up of new ideas for public sector improvement.

\section{Theoretical foundations and premise for an emergent model}

Kable (2008), the publisher of Government computing, estimates that the U.K. public sector Information and Communication Technologies (ICT) budget-spend for 2007-2008 will be in the region of $£ 17 \mathrm{bn}$, rising to $£ 20$ bn by 2012-2013. Much of the motivation by Local and Central Governments justifying this expenditure on e-Government systems is in support of their search to reduce administrative bureaucracy and operational costs, as well as improving the services they offer to businesses, citizens and social groups (Taft, 2001). However, traditional methods of investment decision-making do not easily accommodate such motivations, which often lack a financial return as they are driven by the need to deliver improved services to the citizen or more broadly, those that engage with local Government. Nonetheless, issues associated with benefit, cost and risk management do remain prevalent in the public sector and remain central to robust corporate governance and transparency, more so, given recent spectacular cost over-runs on public sector project, such as those within the U.K. Department of Work and Pensions, which reports a cost over-run of $£ 315 \mathrm{~m}$ (Kable, 2008). Indeed, public sector investments across the world are renowned and indeed often characterised by their spectacular levels of spend yet, often poor levels of return for the tax-payer. Whether this is a result of the apathy and often lack of competitive spirit adopted by those employed in these public sector management roles remains unclear but such factors do little to place the public sector on-par with the effectiveness of the private sector. In the U.K., the Parliamentary Office of Science and Technology (POST) reported that the cost of cancelled or over-budget Government ICT projects over a six-year period (1997-2002) was greater than $£ 1.5$ bn (POST, 2003). However, the scope of much larger costs to the public purse are widespread, especially when one considers that the U.S. Department of Defence reports an annual net operating cost exceeding \$620bn including more than \$30bn for technology - with 2.9 million people, and a supply chain involving 5.2 million items (Fisher, 2008). There is growing widespread acceptance that public sectors across the world need to change and offer improved value to the tax-payer. The driving force behind such public sector funding reviews are clearly cost savings but increasingly, there is a softer, more human-centric motivation, the identified need to create social entrepreneurship and to better promote and create an environment for change. This enabler of public sector reform is increasingly seen as a manifestation of an environment where innovation can flourish, within a culture of continuous improvement, whist using eGovernment as an infrastructure to the support of social entrepreneurship.

e-Government is the process of delivering information and services to customers (citizens, business and public administration) electronically by Government. This process can play a significant role not only in improving services to customers, developing businesses, the economy, and society but also in renewing the role of Government itself. Abie et al. (2004) claim that eGovernment could be considered a powerful tool that can effectively manage and integrate huge amount of existing information, as well as seamlessly integrating citizen interaction with its services. Atallab (2001) claims that there are two primary aspects to the benefits of eGovernment. The first is the transformation of Government operations, which benefits citizens, businesses and the Government itself. This means that the needs of citizens are more likely to be met, and thus allows businesses to benefit by making them both consumers of Government services and providers of services and goods to the Government. It also benefits the Government through reducing operational costs via increasing the efficiency of internal operations. The second aspect is the transformation of governance, which positively affects the relationship between citizens and Governments through improving the interactivity between Government and citizens and thus making it smoother, faster and more responsive.

Efforts to create an e-Government infrastructure are seen as a means to modernise public services, while also promoting an environment of social entrepreneurship. In response to local Governments wanting more support, 
the U.K. Government initiated a programme back in 1999 called Modernising Government (White Paper, 1999), which was seen as a vehicle upon which future agendas would be mounted. Another important and highly relevant initiative was undertaken in 2006, when the U.K. Central Government commissioned a respected public figure to investigate and review public sector efficiency. The report compiled by Varney (2006) presents a critical narrative that calls for improved public sector services, which in turn should deliver improved valuefor-money for the tax-payer. The report argues that to achieve this objective, public sector services will need to exploit e-Government to increase productivity, efficiency, citizen communication and engagement. Against this backdrop of strategic imperative lies the need to achieve such gains by maximising the talent of public sector employees and allowing them to influence change.

In moving to explore the theoretical underpinning of social entrepreneurship within an e-Government context, the authors sought to develop a thesis upon which a propagated model could be developed. Much of the theoretical underpinning supporting a thesis of creating $a$ techno-centric environment where social entrepreneurship can thrive within an e-Government context can be grounded back in the normative institutional theory literature of Selznick (1948) and Scott (1987). Yet, institutional theory within an information systems context is not new, with it having been applied within software development by Adler (2005), at an institutional perspective by Avgerou (2000), business process re-engineering by Boudreau \& Robey (1996) and by Butler (2003) when implementing information systems. The critique of such literature led to the refinement and iteration of the thesis, resulting in a rationale that supported model building yet, maintaining a rationale upon which an emergent model could be eventually tested.

Institutional theory attends to the deeper and more resilient aspects of social structure, which in this case bind together public sector services; with e-Government acting as the facilitator of communication through the delivery of services. It considers the processes by which structures joining together the organisation, including schemas, rules, norms and polices, become established and therefore act as a frame of reference which shape social behaviour.

Hjort-Madsen (2007) explains that the majority of the e-Government literature focuses on prescriptive models for innovations. In addressing this prescription with description, Hjort-Madsen (2007) offers a contextual understanding of the regulative processes, normative systems and cultural frameworks that shape the adoption of information system innovations within the public sector, such that there adoption can be embraced for public sector advantage. Therefore, in using institutional theory as an underpin to an e-Innovations model that promotes social entrepreneurship, while recognising how the adoption of innovation within the public sector is fostered, is where this paper seeks to make its contribu- tion towards the promotion of social entrepreneurship in the public sector.

Ideas cannot be produced on demand or offer any guarantee of worth. Innovators (ideas generators) need the necessary environment in which to generate ideas, while managers need to develop an embedded culture where success is encouraged and yet failure is not stigmatised. The underlying rationale for this research note is about turning good ideas - wherever they arise within the organisation (level within the hierarchy) into major benefits for local communities (demonstration of worth to the tax-payer). In addressing concerns of bureaucracy that stifle innovations, the process being proposed engages a range of stakeholders into an activity through which new ideas, objects and practices are created, developed or reinvented, thus developing social entrepreneurship as well as the management of social entrepreneurs.

\section{e-Innovations within the public sector: proposed process outline}

Government funded research conducted by Irani \& Elliman (2007) identified a lack of joined-up thinking between initial research or development and eventual deployment of systems across the public sector. The following proposed process assumes that some form of common fund is available to all Local Government Authorities (LAs) and which is administered so that it is directed to the most desirable innovations.

The suggested e-Innovations process is itself an innovation. In contrast with the centrally managed ODPM 2003-2005 initiative, it is predicated upon a collective interest in identifying and developing innovations for use across a wide pool of LAs. It sets out to provide a framework, within which change and innovations can flourish and is split into three phases, as presented in Figure 1:

1. Creating ideas and the environment for innovation. It will also provide innovators and innovation managers with the tools that they need.

2. Developing innovative project plans.

3. Selecting the 'best' projects and agreeing the funding contracts.

The creation phase begins by generating ideas through a variety of channels and, in parallel, preparing local authorities (management) to support innovation and entrepreneurship. Both audiences are different and have distinctive requirements. Given appropriate support (as detailed below), the ideas generated by innovators will be developed to the point where they can be 'sold' to the LA management as worthy of serious consideration; LA management will need to be provided with the necessary skills to support this activity at the next phase.

The proposed process removes the possibility of prematurely selecting (possibly driven by internal politics) a single project but rather exploits the bottom-up development of ideas that are supported through social 


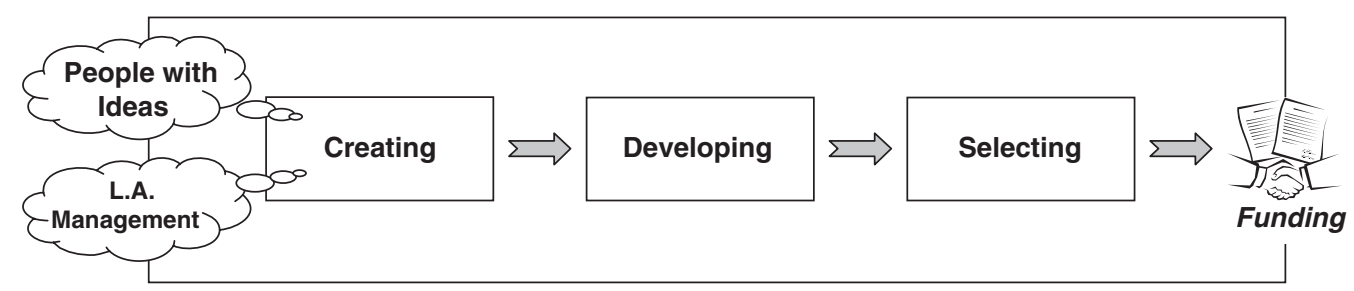

Figure 1 Conceptualisation of ideas-factory.

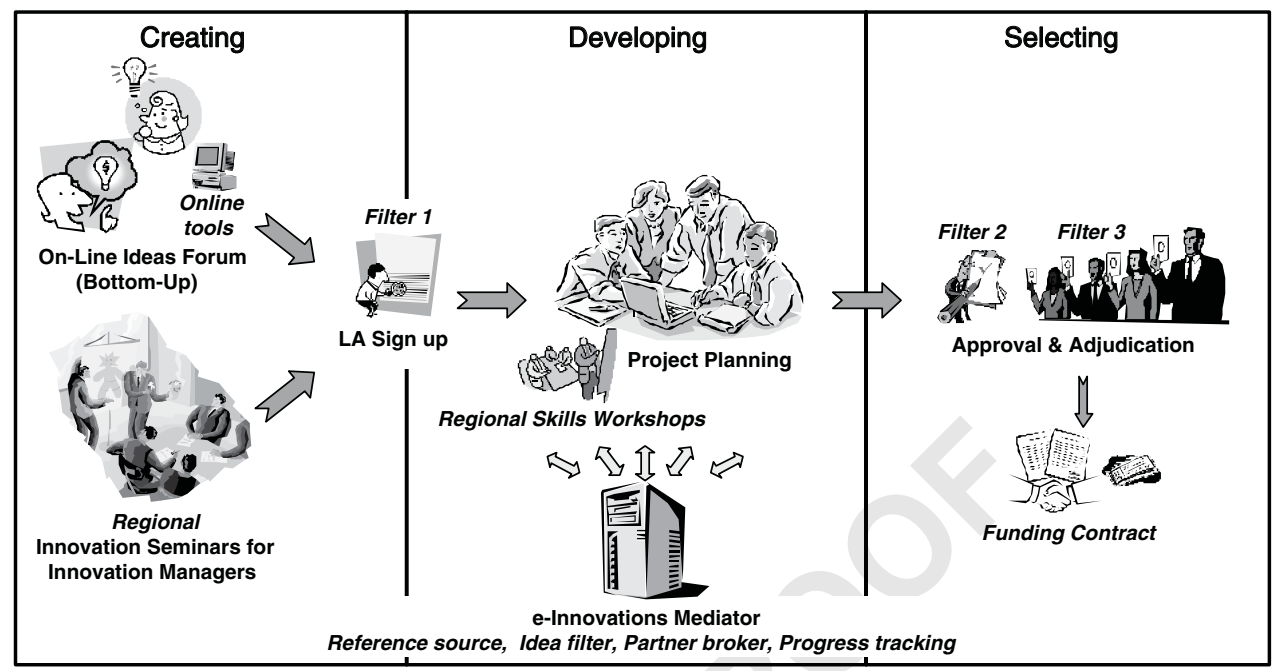

Figure 2 Walk-through of proposed process.

entrepreneurship. In this new model the authorities' executive and political decision-making powers are maintained through their involvement in a series of filters that progressively 'weed-out' less attractive projects as the process proceeds.

The second phase is for the initial ideas to be developed into suitable project proposals. Entry into this phase requires the backing of one or more authorities (the first filter). This first filter breaks the line management veto by allowing the 'backers' to cross silo and authority boundaries. The proposed process will make innovative use of technology such as WebCT to allow - where appropriate - similar innovative ideas from different LAs to be exploited without duplicate funding. This will be realised through content management where collaboration between LA and regional best practice will be encouraged and exploited. During this phase, the planning process will be supported through regional centres with appropriate education and skills training workshops and discussion forums.

The final phase will involve meeting the funding criteria as set out by the administration of the common fund, before a project can enter the selection process. This could be a Central Government body mandated with promoting the development of e-Government or now more widely known as Transformational Government
(Elliman et al., 2007; Irani et al., 2007). Alternatively, it could be a regional assembly or a mutually agreed collective of LAs. This second filter is an independent validity check (go or no-go) on each project rather than a judgement applied to the relative merits of different projects. The local authorities again play an important role in the final selection through their representation on an established college of adjudicators, which is created to prioritise projects.

\section{e-Innovations: proposed process details}

The process being proposed centres around two target stakeholder groups; people at every level in the organisation who generate ideas, then managers that support the cultivation and realisation of these ideas. Figure 2 represents a walk-through of the phases in the proposed process as well as the underlying detail.

\section{Online ideas forum: bottom-up process}

The initiation of an innovation typically results from a reservoir of ideas that range from the wacky and unstructured to those carefully crafted and articulated. Knowledge and practices are seen as the trigger to instigate change. Anyone with an idea should have the opportunity to debate within an open forum where an exchange of ideas can exist. This activity is targeted at all 
levels of LA staff, by providing them with an innovative online ideas forum. It will use online teaching technology such as WebCT to provide guidance on the selfassessment of ideas for high feasibility, low-cost and high community value.

\begin{tabular}{llll}
\hline Idea de- & Feasibility (high/ & Cost (high/ & Community value (high/ \\
scription & medium/low) & medium/low) & medium/low)
\end{tabular}

This will ensure that people with ideas are encouraged to think through the consequences of their innovation, and to present well founded proposals.

Rather than to apply an early veto to the idea, the process should simply allow those without merit or support to fade away at the sign-up stage.

\section{Innovation seminars}

In parallel with seeking ideas from all levels in LA, there is the need to prepare local authorities more formally to participate within the process and where necessary provide the required skills training. The bottom line is to recognise that LA (the end-users), individually and collectively, will be the final arbiters of the ideas that eventually develop into fully fledged projects.

These regional seminars will be aimed at middle to senior staff with authority to champion innovative developments within their organisation; support to allow managers to navigate innovation through their organisation will be enfranchised. Local authorities will be encouraged to identify staff that can represent the authority as 'social entrepreneurs' in developing project proposals from ideas that come from within their organisation. Issues to be resolved (that will be sought through a web survey that will target potential seminar participants) will form the curriculum content for the seminars and the follow-up support. Thus, the system will ensure relevance in content of the seminars.

\section{Local authority sign-up}

The broad principle of matched funding is one that is largely expected to be maintained within e-Government funding. Eventually local authorities must identify those projects to which, if supported by the sponsor, they will contribute the necessary resources. At this stage ideas are filtered by the social entrepreneurs, and others, with LAs identifying those ideas they are prepared to back by supporting the development of detailed project plans. It is anticipated that an idea from one authority may be taken up by another and that projects may be undertaken collaboratively. Thus, the sign-up process needs to be supported by some form of 'dating' service to link up related ideas and interested authorities; this will be realised through content management where collaboration between LAs will be supported.

\section{Project planning}

Transformation from idea to executable project will require specific skills and support. In promoting an enterprise culture, people with good ideas should not be excluded from developing them simply because they lack the skills or authority. This will be delivered through local workshops where more promising ideas will be developed further. Such workshops will also act as forums to discuss and debate details of the innovations and for others to play devils-advocate yet maintaining no formal agenda. These are aimed at the original proponents possibly supported by a more senior member of staff or the social entrepreneur. Following the workshops, detailed project plans must be prepared. These will include issues to be resolved and the level of support needed to take an idea forward.

\section{e-Innovations mediator}

Creating a more open environment for exploring and developing ideas will require support through training, brain-storming, discussion-lead workshops and resource planning, which are all capable of reaching a large number of people in LA. In an e-Government context, an online computer-based system should only be used as a filtering mechanism. The primary function of the online mediation service will be to support initial development and filtering of ideas, discussion forums, brokering collaborative development of project proposals and tracking progress of projects. It will also support the college of adjudicators in scoring and ranking projects.

\section{Approval and adjudication}

By this stage, the authorities will need to confirm their willingness to commit resources to a project plan. As plans are completed they will be checked by the funder, or its designated consultants, and signed off as suitable (filter 2). This is not intended to be the approval of funding but a commitment that it is fit-to-fund, if selected - the principle to be applied is that the funder may veto an unsatisfactory project but that project selection will be based on a wider appraisal of merit. In addition to direct support for projects, LA (and possibly others) will nominate a college of adjudicators. These adjudicators will rank or score approved projects (scale to be defined) such that an overall ranking can be determined (the final filter).

The funder may wish to limit access to the overall ranking; thus, preventing individual adjudicators from manipulating the position of specific projects and therefore the outcome of the process. Issues open to be determined will be the acceptance criteria as defined by the funder, the scoring scheme, the overall ranking algorithm and the nature of contracts and the times and amounts to be allocated. In here lies further work, some mathematical but, which falls outside the scope of this research note, which is to proffer a techno-centric environment where social entrepreneurship can thrive within an e-Government context. 


\section{Conclusions}

This research note has sought to develop a process to support local authorities in their quest to become more entrepreneurial and thus supportive of innovation through a structured process. The underpinning rationale is well grounded theoretically, with the emergent model practically applicable within the public sector. Indeed, the next phase of the research is to move into a more applied phase that will allow the testing and refinement of the model; thus, leading to a process where innovation can be fostered and nurtured.

All through the ODPM initiative in 2003-2005 and in its follow-up evaluation as reported by Anon (2007), the administration of e-Government has struggled with creating an environment where innovation can be nurtured and thus, occur. The need for Central Government to be 'in the driving seat' and for processes to be perceived as publicly accountable produces a conservative and risk-averse culture that only seeks to stifle innovation and thus, maintain the status quo. The paradox is that management can only stimulate innovation by standing back and not trying to manage the flow of ideas. The key under the proposed model is to manage the process and let the ideas flourish.

Although it is recognised that the proposal is an unproven process, it does seek to serve as a process that threatens the conservative and risk-averse culture endemic in the public sector. This is clear through the way it enfranchises people with the new ideas, irrespective of their place in the hierarchy. It was originally conceived as a national process but there is no reason why it should not be adopted over a smaller administrative area. Nor need it be driven from the top - a collective like the 'Yorkshire Digital eco-system' and 'PIE' (Topham, 2008) could easily adopt the process.

Having tabled the challenge, the authors await the public body innovative enough to adopt it, so that the process can be refined in operation.

\section{Acknowledgements}

We acknowledge the support from the Information Systems Evaluation and Integration Group (ISEing), which supported part of this work. ISEing was established at Brunel University under a research grant from the U.K. Engineering and Physical Sciences Research Council (EPSRC: GR/R08025/01). Ideas for this position paper came out of an EPSRC-funded grant: 'e-Government Integration and Systems Evaluation (e-GISE)'. EPSRC Ref: [GR/T27020/01]. We acknowledge the support and additional comments provided by both Professors Ray Paul and Richard Baskerville. Their contribution did help improve the manuscript.

\section{About the author}

Zahir Irani is the Head of the Business School at Brunel University (U.K.). Having worked for several years as a project manager, Professor Irani retains close links with industry. He has also consulted for what was the ODPM in the U.K. on e-innovations in the public sector, as well as for international organisations such as HSBC, Royal Dutch Shell Petroleum, GlaxoSmithKline and BMW. Professor Irani is a multi-disciplinary researcher and founding member of the ISEing (http://www.iseing.org), and works in the area of information systems evaluation and application integration. He has been recognised as the Hooker Distinguished Professor at McMaster University (Canada) as well as being a visiting professor at several Universities, worldwide. He is the Editor of the established Journal of Enterprise Information Management as well as Editor of Transforming Government: People, Process and Policy. He is also actively involved with the European Mediterranean Conference on Information Systems (emcis.org). He has co-authored teaching text books and written almost 200 internationally refereed papers. He regularly publishes his scholarly work in leading journals, which include Communications of the ACM, IEEE Transactions on Engineering Management, Information \& Management, Information Systems Journal, Journal of Management Information Systems, European Journal of Operational Research, Journal of Operational Research and European Journal of Information Systems. Professor Zahir
Irani has received numerous contracts, grants and awards from funding bodies that include the Engineering and Physical Sciences Research Council (EPSRC), Economic and Social Research Council (ESRC), Royal Academy of Engineering, Australian Research Council (ARC), QinetiQ, Department of Health and European Commission.

A. D. (Tony) Elliman is a reader in Information Systems and Computing with an interest in the development of information systems for the public sector. He is a founding member of the ISEing (http://www.iseing.org) and has experience of using simulation techniques in a variety of contexts, including IT project evaluation. He is also actively involved with the European Mediterranean Conference on Information Systems (emcis.org). He works closely with the Chartered Institute of Public Finance and Accountancy (CIPFA) Improvement and Quality Network on e-Government projects. Having trained as an electrical engineer with International Computers Limited, Dr. Elliman has a broad background, having taught many aspects of computing including information systems development, software engineering, distributed systems and hybrid simulation. As a chartered engineer, he has provided software consultancy services to Government, academic and private sector organisations, and has benefited from funding sources that include EPSRC, QinetiQ and the EU. 


\section{References}

ADLER PS (2005) The evolving object of software development Organization 12(3), 401.

ANON (2007) Framework for innovation in local government. URL: http:// www.exploringinnovation.org.uk/framework-for-building-innovation (last accessed 24 February 2008).

AVGEROU C (2000) IT and organizational change: an institutionalist perspective. Information Technology \& People 13(4), 234.

BOUDREAU M-C and ROBEY D (1996) Coping with contradictions in business process re-engineering. Information Technology \& People 9(4), 40-49.

BUTLER T (2003) An institutional perspective on developing and implementing intranet- and internet-based information systems. Information Systems Journal 13(3), 209-231.

E-ENVOY, (OFFICE OF) (2002) U.K. online annual report 2002. dated November 2002, HMSO, London, U.K., URL: http://archive.cabinetoffice.gov.uk/e-envoy/reports-annrep-2002-pdf/\$file/annualreport02.pdf (last accessed 24 February 2008).

ELLIMAN T, IRANI Z and JACKSON P (2007) Establishing a framework for eGovernment research: project VIEGO. Transforming Government People, Process and Policy 1(4), 364-376.

FISHER D (2008) Boosting performance in public sector IT, McKinsey quarterly, strategy, July.

HJORT-MADSEN K (2007) Institutional patterns of enterprise architecture adoption in government. Transforming Government: People, Process and Policy 1(4), 333-349.

IRANI Z and ELLIMAN T (2007) Electronic transformation of government in the U.K.: a research agenda, a project VIEGO report, ISEing, Brunel University. URL: http://www.iseing.org/iseing/Resources/VIEGO\%20Report.pdf (last accessed 10 August 2007).

IRANI Z, ELLIMAN T and JACKSON P (2007) Electronic transformation of government in the U.K. European Journal of Information Systems 16(3) 327-335.
IRANI Z, LOVE PED, ELLIMAN T, JONES S and TheMistocleous M (2005) Evaluating e-government: learning from the experiences of two U.K. local authorities. Information Systems Journal 15(1), 61-82.

IRANI Z, LOVE PED and JONES S (2008) Learning lessons from evaluating eGovernment: reflective case experiences that support transformational government. Journal of Strategic Information Systems 17(2), 155-164

IONES S, IRANI Z, SHARIF AM and THEMISTOCLEOUS M (2006) EGovernment evaluation: reflections on two organizational. Thirty-ninth annual Hawaii international conference on System Science (HICSS-39), (CD Proceedings), 5-7 January, Island of Kauai, Hawaii, U.S.A.

KABLE (2008) Government Computing Magazine 22(4), 12-13.

NYE J Jr. (1999) Information technology and democratic governance. In Democracy.Com? Governance in Networked World (KAMRCK EC and NYE J Jr., Eds), pp 1-18, Hollins Publishing Company, Portsmouth, $\mathrm{NH}$.

Parliamentary Office of Science and Technology (POST) (2003) Government IT Projects. HMSO, U.K.

TAFT DK (2001) Raising the e-Government banner, CRN, 19 March, pp. 32-38.

TOPHAM S (2008) 'Yorkshire digital eco-system' - removing the barriers. Magna Centre, South Yorkshire, 31 January 2008, URL: http://www.wspes.org/statiche/WS-II.pdf (last accessed 24 February 2008).

ScoTT WR (1987) The adolescence of institutional theory. Administrative Science Quarterly 32(4), 493.

SELZNICK P (1948) Foundations of the theory of organizations. American Sociological Review 13(1), 25-35.

VARNEY D (2006) Service transformation: a better service for citizens and businesses, a better deal for the taxpayer. HM Treasury.

WHITE PAPER (1999) Modernising government. http://www.archive.official-documents.co.uk/document/cm43/4310/4310.htm (last accessed 19 February 2008). 